\title{
AUTORRETRATO: \\ La impresión y (des)composición de un momento de rostro
}

\author{
Amilcar Borges de Barros \\ Docente del Departamiente de Danza \\ de la Facultad de Artes de La Universidad de Chile \\ amilcarbde@gmail.com
}

\section{Auto retrato de una infancia en (des)composición}

\begin{abstract}
"la cualidad documental de la huella óptica (...) que arranca lo "real" de un espacio-tiempo único y contingente, trasladándolo a un espacio memoria, plural y múltiplemente citable y anexable, se tocan concretamente en la foto misma y se precipitan sobreimpresos dos tiempos discontinuos en sentido social. Varios tiempos y una sola imagen, por tanto imagen estratificada. Una discronía.” (KAY, 2005, p.25/27)
\end{abstract}

La fotografía es un desprendimiento, una captación y una detención de un instante, de un tiempo presente que se extiende y tensiona las evocaciones de las imágenes del acto mnemónico, es decir entre las imágenes de un recuerdo y la fotografía de este recuerdo se articulan disonancias temporales, perceptivas, históricas y simbólicas. La corporalidad que encarna la imagen del recuerdo (re)produce alteraciones y difracciones. Estas son generadas por el acto mnemónico que intenta desde las percepciones (re)configurar las imágenes del pasado a partir de su (re)aparición en el presente. Por otro lado la imagen fotográfica es la captación de una huella óptica que detiene el momento, que lo extiende y fisura desde la perspectiva del fotógrafo el relato y el tiempo. Por lo tanto delante de una imagen fotográfica estamos también delante de la sustracción del presente, de la interceptación del instante y de la suspensión y extensión del tiempo; que es impreso, expreso y expuesto como fragmento óptico de un relato que tensiona, desde una intensidad estética, los sistemas propioceptivos, perceptivos y sinestésicos de los recuerdos, registros y archivos de la corporalidad misma. 
Dialogar con el archivo fotográfico requiere de antemano entender la memoria como una noción de encuentros diacrónico/sincrónico ${ }^{1}$ donde las huellas, textos e imágenes culturales emergen desde varias distancias y perspectivas diferenciales, haciendo del acto mnemónico una interpenetración administrada por un trazado imaginario $^{2}$ que configura y modifica el presente. Por lo tanto la rememorización histórica podría entenderse como un encuentro cultural ${ }^{3}$ continuo y ontológico que tensiona y configura lo identitário, según Parret(2008, p.163), la memoria pone al sujeto en contacto con una "versión interior", y ese poder de la memoria trasciende las palabras profesadas en las lenguas históricas. Este encuentro cultural identitário de la percepción o "visión interior" con la fotografía familiar pone de manifiesto la impresión del archivo fotográfico como una incisión fenomenológica que extiende lo semántico de la materialidad hacia la intersubjetividad del recuerdo como imagen/spectrun que es captada y desplazada. La fotografía emerge entonces, desde esta intersubjetividad de las pulsiones escópicas, como un archivo dialéctico y sinestésico de carácter actante y expansivo entre lo público y lo privado, entre la percepción y el recuerdo, entre la realidad y el imaginario generando y subjetivando dislocaciones e interpenetraciones sociales, económicas, históricas, políticas, familiares y culturales. En las palabras de Derrida:

(...) la institución misma del acontecimiento archivable, no solo condiciona la forma o la estructura impresora, sino el contenido impreso de la impresión: la presión de la impresión antes de la división entre lo impreso y lo impresor. (DERRIDA, 1987, p.26)

Delante de las huellas y de las impresiones que emergen de un archivo fotográfico familiar se adhieren las trazas y las capas de una memoria corporal, individualizada y contextualizada. Esta adherencia genera una difracción entre la fotografía de mi niñez y la evocación de la imagen de mis recuerdos de infancia. Esta tensión entre lo fotografiado y lo evocativo hizo con que yo emprendiera en el año 2007, un viaje hacia la hacienda de mi familia en Brasil en búsqueda de una fotografía de estos recuerdos. Más específicamente, estaba obsesionado por una fotografía que tenía mi abuela. Esta fue realizada en una de nuestras vacaciones en la hacienda donde 
todos los nietos y de manera individual tuvimos que vestirnos y peinarnos especialmente para la ocasión. Mi abuela enmarco las fotos que luego fueron colgadas en la pared del living. He crecido con estas fotografías, con esta imagen de mi rostro colgado en la pared y que a cada año se diferenciaba y se distanciaba de mi realidad, sin embargo, delante de esta fotografía los tiempos y mis rostros se interseccionan en una sobreimpresión diacrónica, sinestésica y perceptiva. Haciendo con que las imágenes del archivo de mis rostros anteriores excedan la propia percepción de mi rostro actual. Rostros que fueran y son multiplicados, (re)configurados y adheridos a un archi-archivo ontológico, propioceptivo e inagotable. Esta trasformación, esta sobreimpresión de rostros se hizo evidente al encontrarme con la fotografía de mi infancia en proceso de descomposición y constatar que esta se diferenciaba de la fotografía de mis recuerdos. Esta circunstancia inesperada de abandono evidencio la crisis del almacenamiento y de la conservación de mi memoria fotográfica familiar e individual. Al encontrarme con esta fotografía de mi infancia en descomposición, mi intención no era restaurarla, y si registrar, captar, sustraer y (re)significar desde lo fotográfico el instante, y las huellas de la alteración y de la (des)aparición de una imagen auto-biográfica.

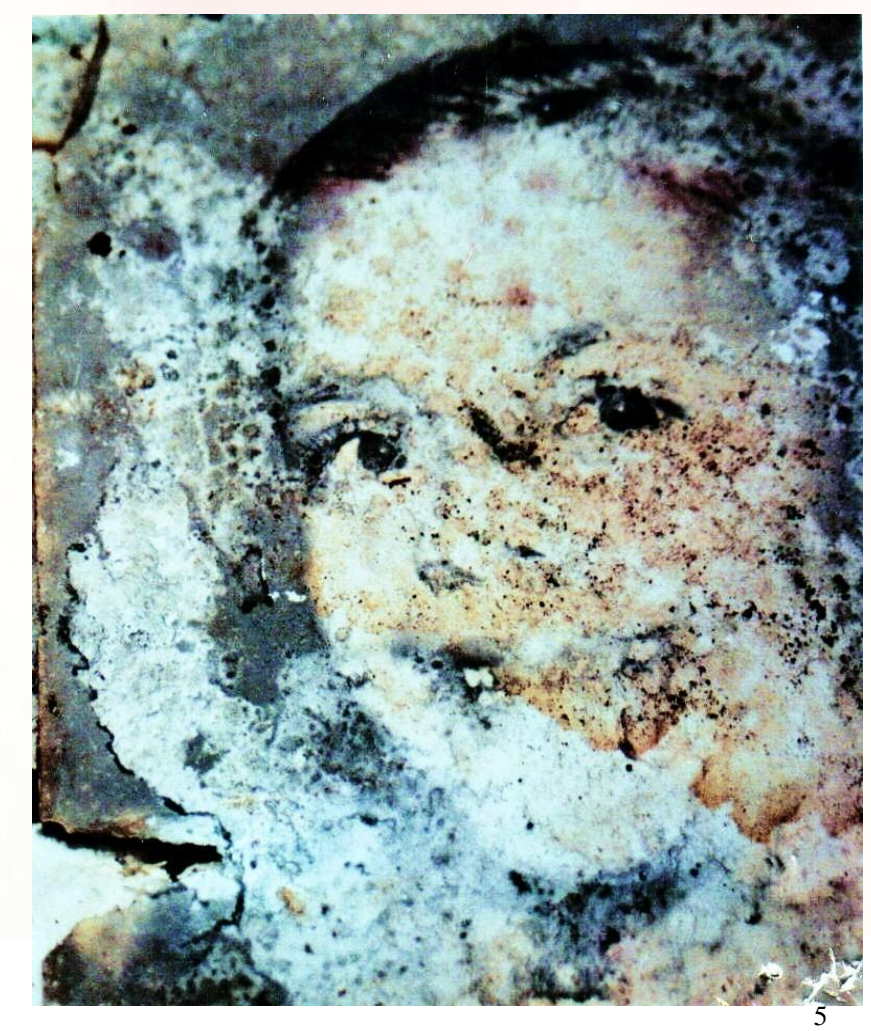

(...) la imagen fotográfica, incluso en la medida en que es un rastro (y no una construcción elaborada con rastros fotográficos diversos), no puede ser la mera transparencia de lo sucedido ${ }^{6}$ 


\section{La (re)producción de un archivo de rostros y la configuración de la autoalteridad.}

3.

El rostro es por naturaleza primer plano, con sus superficies blancas inanimadas, sus agujeros negros brillantes, su vacío y su aburrimiento. Rostro-bunker. Hasta el punto que si el hombre tiene un destino, ese seria escapar al rostro, deshacer el rostro y las rostrificaciones, devenir imperceptible, devenir clandestino, no por un retorno a la animalidad, ni tan siquiera por retorno a la cabeza, sino por devenires (...) ojos que uno atraviesa en lugar de mirarse en ellos ${ }^{7}$.

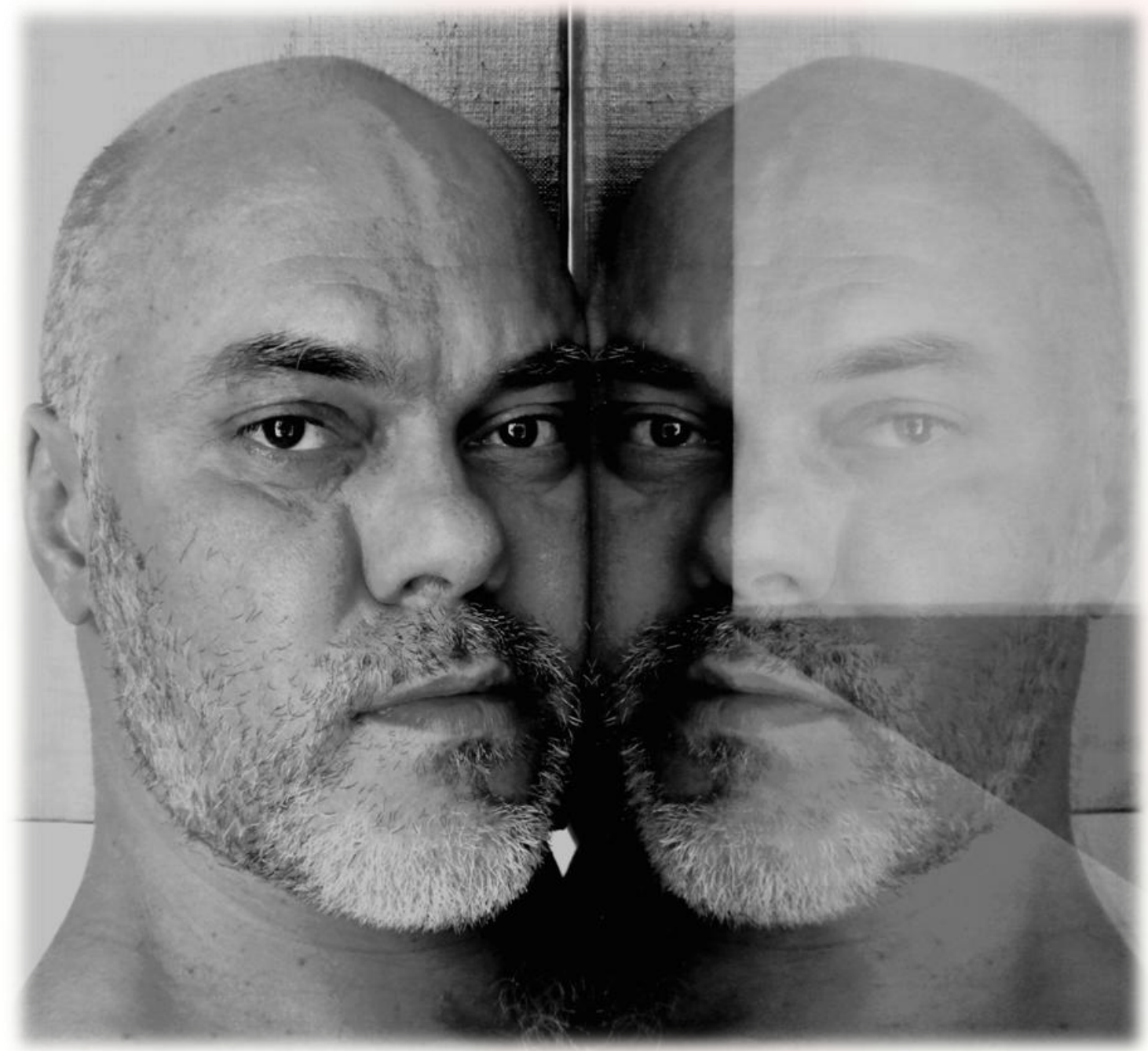

El autorretrato en este ensayo fotográfico ha sido desarrollado a partir de la sobreexposición y yuxtaposición de un archivo de escenas de rostros que fueron captadas durante veinte y cinco días en dos momentos: al despertar y al final de la noche antes de acostarse. Estas fotografías constituyen el archivo y la escena con lo cual 
oscilan y se tensionan la imagen mnemónica idealizada, la imagen del rostro percibido y la configuración del rostro como una imagen fotográfica. La intención de construir este archivo es establecer un lenguaje escópico que se vincula con la voluntad de articular y captar en imágenes lo que podríamos llamar de un momento de rostro, es decir el autorretrato como una alteridad que disloca y (des)conoce el propio rostro haciendo de la percepción una del rostridad que se (di)fiere y se expande rizomáticamente como espectro/imagen. En este ensayo fotográfico los procedimientos de (re)constitución de la escena es decir, del rostro como pose, huella e impresión enuncia y señala el autorretrato como una alteridad, como una multiplicidad de rostros en continua (de)formación de una semejanza que es diferenciada desde una experiencia estética perceptiva. Estar delante de la autoimagen que (a)parece captada y elaborada fotográficamente hace del rostro/foto un archivo inestable cuyo recorrido devela trazos, huellas y rasgos que se enfrentan y se constituyen desde la oscilación y difracción de la mirada doble, soy un rostro sin reflejo que se presenta como materialidad opaca que se (des)conoce allá y acá. No obstante entre el rostro imaginario, el rostro configurado y el rostro percibido emergen los vestigios de un intersticio que desdibuja lo semejante y lo identitário y posiciona la rostridad como un territorio, una frontera y un extrañamiento que es absorbido escópicamente por una (re)producción y (des)composición fotográfica que genera desde el desgaste del individuo su autoalteridad.

A decir verdad, no soy ni sujeto ni objeto, sino más bien un sujeto que si siente devenir objeto: vivo entonces una microexperiencia de la muerte (del paréntesis): me convierto verdaderamente en espectro. 
La identidad en el autorretrato es una enunciación etnológica que en una primera instancia se instala sinestésicamente como imagen (re/des)conocida y descodificada al mismo tiempo y, es capta como espectro opaco, fractal, relacional y múltiple de la producción y capitalización tanto de la autoalteridad como de las identificaciones culturales. El rostro en el autorretrato es una incisión de la percepción y de la trasformación continua. Es una fisura topológica que hace emerger desde la imagen, el rostro como un mapa y un recorrido estético experiencial de las apariciones del espectro fotográfico, es decir el autorretrato es la percepción y de la trasformación continua de un devenir otro. El (re)conocer el uno en el otro es la resultante de una pulsión escópica y háptica que (re)construye y (re)configura resonancias estéticas y neuropolíticas ${ }^{11}$ que 
instauran y activan una multiplicidad de sentido; es decir la aparición, el aparecer y la supuesta apariencia empática del rostro son una afección y una diferenciación que genera, en una primera instancia, una cognición social y crítica entre la identificación y el extrañamiento, para luego hacer de esta una autoalteridad construida y constituida desde la diferenciación y (re)adecuación psicosocial en algunos casos y, en otros; una desterritorialización opaca de la intersubjetividad de los espejos/refractarios de la cognición misma.

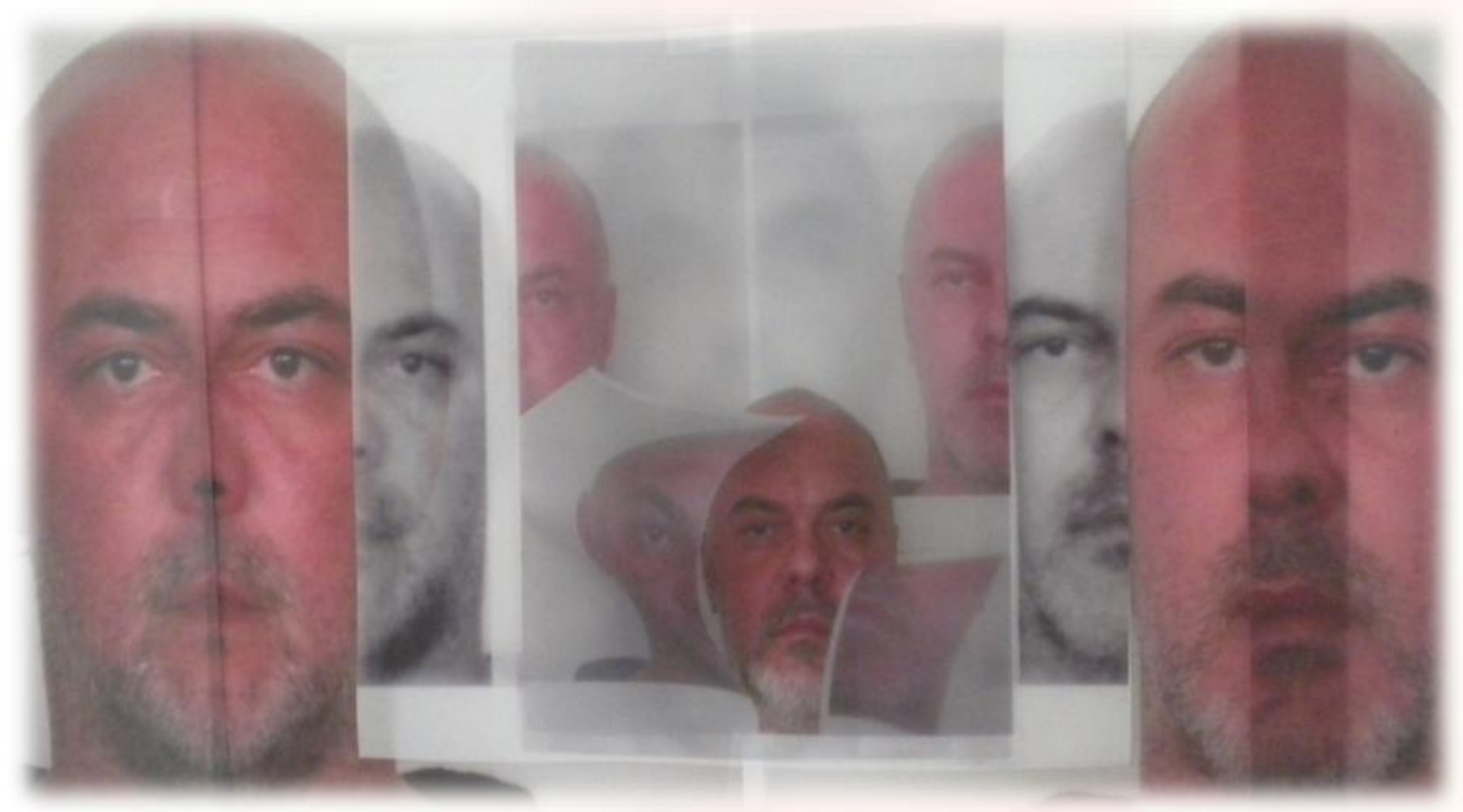

El autorretrato es un rostro (re)-presentado y (re)constituido escénicamente desde archivos yuxtapuestos y sobreexpuestos. El autorretrato se configura a partir de la foto de la foto de la fotografía que fue impresa y expuesta para instaurar la impresión, rizomática, radicante y poiética de un rostro que se (re)produce. Desde esta perspectiva la rostridad es una afección, una contravención de refracciones, una coacción de desestabilización ontológica generadas por la sobreexposición y multiplicación de los pliegues del original en la copia. La impresión, yuxtaposición y sujeción del autorretrato como un momento de rostro, desdibuja el origen y disloca la identidad y el lenguaje 
idiopático del fotógrafo hacia su autoalteridad, en este instante el autorretrato se instala como lenguaje y discurso escópico. Este yo/rostro/imagen del autorretrato es la captación de rostros multiplicados y adheridos a un archi-archivo ${ }^{13}$ ontológico que confronta y fisura desde su tendencia en devenir otro, la rostridad de la percepción y el lenguaje. Lacan califica el yo como el "lugar de desconocimiento". Podríamos decir entonces que el autorretrato es el lugar de la mirada que se presenta como el punto ciego de una escena intima que se desplaza hacia la deriva, donde el fotógrafo se (des)conoce y (re/des)constituye su autoalteridad a partir de las intercesiones entre los rostros de la aparición fotográfica, entre los rostros de las percepciones mnemónicas y los rostros de un imaginario estratificados. Es así como la impresión intenta sostener en la captación fotográfica la enunciación de este lugar transindividual, cuyo recorrido sinestésico, perceptivo y estético hace del rostro un excedente de la cabeza. Entre la localización psicofisiológica del rostro y su huella de irradiación se configura una territorialidad que se extiende del individuo a la multitud. El autorretrato es una cartografía que se presenta como un cumulo de repeticiones y refracciones continúas y diferenciadas del sí mismo y de sus devenires, que son afectados y afectan en la (re)producción del rostro como un imaginario cultural/biográfico. En suma, el uno, esta imagen idealizada y subjetiva de ser uno es también el imaginario de ser varios: es una donación y trasformación continua de rostros, es una instancia sinestésica, neuropolítica y perceptiva en la cual el rostro se encarna culturalmente y socialmente desde las pulsiones y fisuras de un imaginario de rostridad superpuestos. Este momento de rostro es una (de)formación continua que es captada y expuesta fotográficamente como una fisura que desdibuja las fronteras enunciando el extrañamiento y la aparición del extranjero que se asemeja pero se desplaza como un (des)conocido que inscribe etnológicamente la autoalteridad. El rostro es una oscilación siniestra ${ }^{14}$ y un campo de probabilidades que instala desde su captación y (re)producción fotográfica la dislocación, recorrido y trayectoria de la imagen como una inmanencia y huella experiencial, aistética y rizomática de lo cotidiano. 


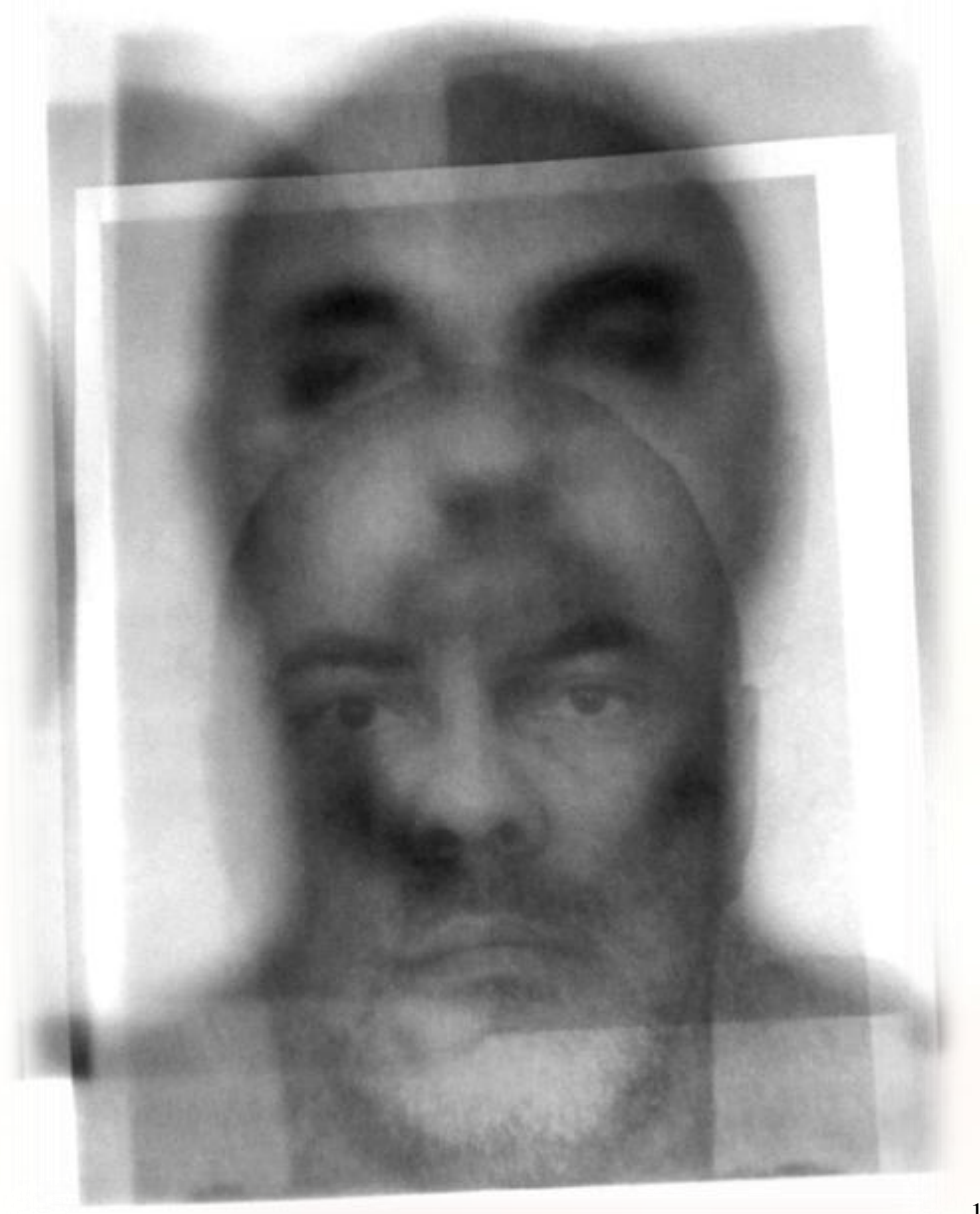

Una lengua siempre está atrapada en rostros que anuncian sus enunciados, que los lastran respecto a los significantes dominantes y a los sujetos concernidos. Las opciones se guían y los elementos se organizan por los rostros: la gramática común es inseparable de una educación de los rostros. El rostro es un verdadero porta-voz. Así pues, no sólo la máquina abstracta de rostridad debe proporcionar una pantalla protectora o un agujero negro ordenador, sino que los rostros que ella produce trazan todo tipo de arborescencias y de dicotomías, sin las cuales el significante y lo subjetivo no podrían hacer funcionar aquellas que les corresponden en el lenguaje. ${ }^{16}$

El autorretrato se presenta como un dispositivo perceptivo y escópico que (des)construye el rostro del autor desde una etnología escópica de lo cercano. El relato o la visualidad que se desprende del rostro configurado es un metafenómeno que emerge sobrecodificado desde la intersubjetividad de la imagen que fue captada y pensada para ser expuesta como el lenguaje escópico de una autoalteridad enunciada. 


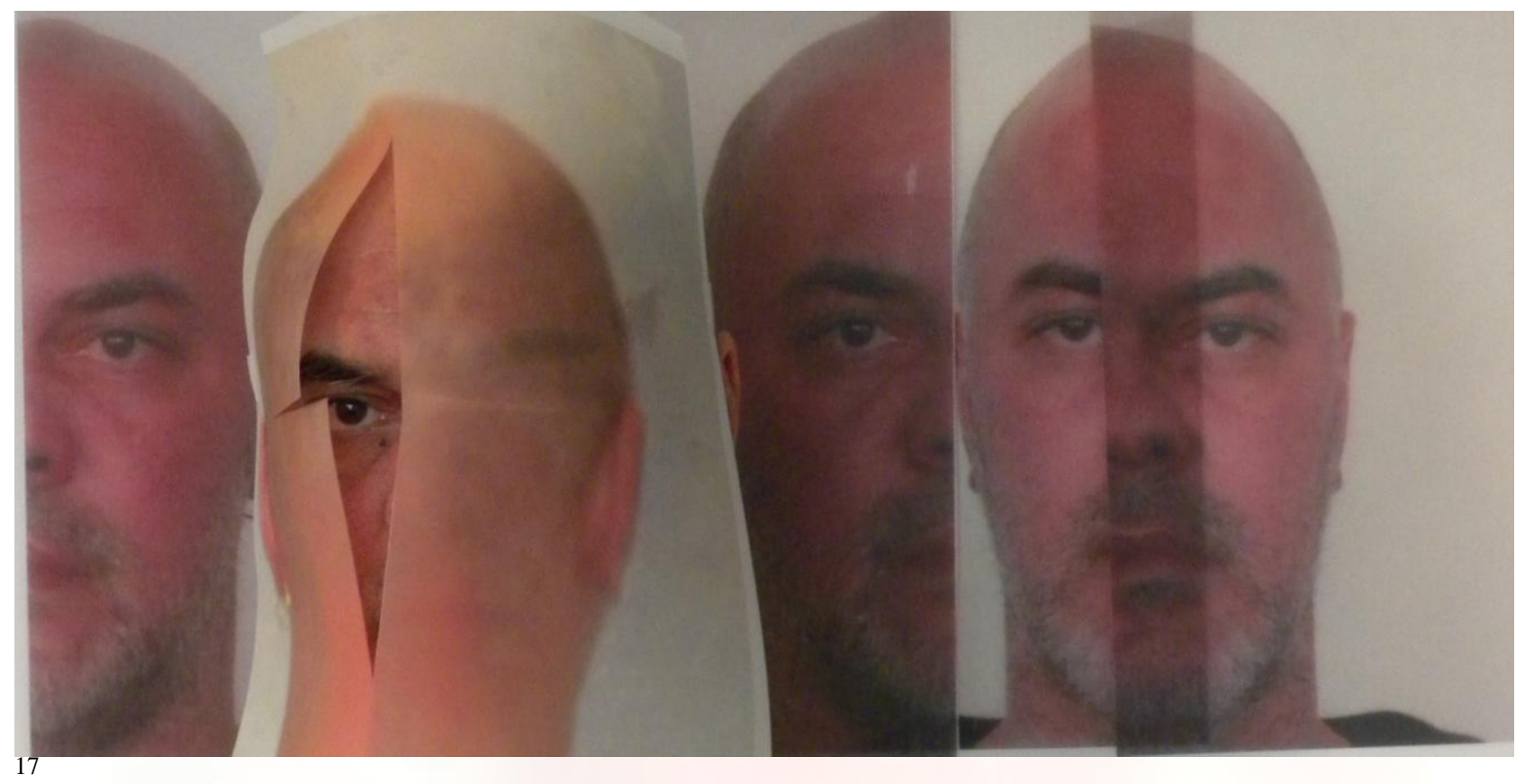

${ }^{1}$ Este concepto diacrónico sincrónico es planteado por Giorgio Agamben en "Infancia e historia" como un recorrido que tensiona la linealidad histórica con la curva hiperbólica, estableciendo así distancias diferenciales entre los hechos según el recorrido

${ }^{2}$ Este trazado imaginario sucede desde un recorrido dialógico entre el presente que enuncia la traza/índice/ huella como eje de evocación de un pasado

${ }^{3}$ Quiero señalar que el concepto de encuentro cultural como reconocimiento y recuperación del ethos latinoamericano se suscribe al planteamiento realizado por Morande en "Cultura y modernización en América Latina", pero lo traslado hacia un recorrido mnemónico constante donde el individuo actualiza, reconoce y recupera las marcas/huellas culturales de su identidad publica y privado

${ }^{4}$ Jaques Derrida en el Mal de archivo, se refiere a la noción de archí-archivo" como una dimensión arcóntica de la lógica y la semántica del archivo, de la memoria y del memorial, de la conservación y de la inscripción que ponen en reserva (store),acumulan, capitalizan, almacenan una casi infinidad de capas, de estratos de archivo a la vez superpuestos, sobreimpresos y envueltos los unos en los otros".

${ }^{5}$ Fotografía de una infancia en (des)composición. Archivo del autor.

${ }^{6}$ Sontag, Susan, Ante el dolor de los demás, pg23, Ediciones Santillana, España, Madrid, 2004.

${ }^{7}$ Deleuze, Gilles y Guattari Félix, “ Mil mesetas: Capitalismo y esquizofrenia“, pág.176, Editorial Pre-textos, España, Valencia, 2008

${ }^{8}$ Autorretrato sobre vidrio y refracciones. Archivo del autor.

${ }^{9}$ Barthes,Roland, La camara lúcida, Editorial Paidós, pág.46,España, Barcelona,1989.

${ }^{10}$ Difuminaciones territorial de un momento de rostro. Archivo del autor.

${ }^{11}$ Para un mayor comprhensión del término ver en Iacoboni, Marco, "Las neuronas espejos: empatía, neuropolítica, autismo, imitación o de cómo entendemos a los otros“, Editorial Katz, Argentina, Buenos Aires, 2009

${ }^{12}$ Acumulaciones de rostros : fotos sobre fotos. Archivo del autor

${ }^{13}$ Derrida, Jacques, en “ Mal de archivo: una impresión freudiana, Editorial“ Trotta, España, Madrid, 1997.se refiere a la noción de archi-archivo:" como una dimensión arcóntica de la lógica y la semántica del archivo, de la memoria y del memorial, de la conservación y de la inscripción que ponen en reserva (store),acumulan, capitalizan, almacenan una casi infinidad de capas, de estratos de archivo a la vez superpuestos, sobreimpresos y envueltos los unos en los otros

${ }^{14}$ Esta dimensión siniestra está relacionada con las correlaciones que hace Freud entre las palabras alemanas unheimlich y heimlich, el siniestro se articula desde esta perspectiva etimológica como una oscilación relacional entre lo familiar, lo conocido, los secretos y lo no develado.

${ }^{15}$ Desfase de una yuxtaposición de rostro. Archivo del autor. 
${ }^{16}$ Deleuze, Gilles y Guattari Félix, “ Mil mesetas: Capitalismo y esquizofrenia“, pág.184, Editorial Pre-textos, España, Valencia, 2008.

${ }^{17}$ Inversión simétrica y fisura de rostros. Archivo del autor.

\section{REFERÊNCIAS}

BARTHES, Roland, La camara lúcida, Editorial Paidós, pág.46, España, Barcelona,1989

DELEUZE, Gilles y Guattari Félix, “ Mil mesetas: Capitalismo y esquizofrenia“, pág.184, Editorial Pre-textos, España, Valencia, 2008

DERRIDA, Jacques, Mal de archivo: una impresión freudiana.; pg.26, Editorial Trotta, España, Madrid, 1997.

IACOBONI, Marco, "Las neuronas espejos: empatía, neuropolítica, autismo, imitación o de cómo entendemos a los otros“, Editorial Katz, Argentina, Buenos Aires, 2009

KAY, Ronald, "Del espacio de acá", pg25/27, Ediciones Metales Pesados, Chile, Santiago 2005

PARRET, Herman, "Epifanías de la presencia: ensayos semio-estéticos", pg.163, Ediciones Universidad de Lima Fondo Editorial, Perú, Lima, 2008

SONTAG, Susan, Ante el dolor de los demás, pg23, Ediciones Santillana, España, Madrid, 2004 